\title{
Commentary: Robotic anatomic lung resection: Raising the bar of our expectations in treating lung cancer
}

\author{
Abbas E. Abbas, MD, MS, FACS
}

\footnotetext{
From the Division of Thoracic Surgery, Department of Thoracic Medicine and Surgery, Lewis Katz School of Medicine at Temple University, Philadelphia, Pa.

Disclosures: Dr Abbas is a paid consultant for Boston Scientific, Inc and Intuitive Surgical, Inc. Neither entity was involved in the preparation of this report.

Received for publication Sept 8, 2019; revisions received Sept 8, 2019; accepted for publication Sept 10, 2019; available ahead of print Nov 19, 2019.

Address for reprints: Abbas E. Abbas, MD, MS, FACS, Department of Thoracic Medicine and Surgery, Temple University Health System, Lewis Katz School of Medicine, 3401 N Broad St, Suite C-100, Philadelphia, PA 19035 (E-mail: abbas.abbas@temple.edu).

J Thorac Cardiovasc Surg 2020;159:689-90

$0022-5223 / \$ 36.00$

Copyright (C) 2019 Published by Elsevier Inc. on behalf of The American Association for Thoracic Surgery https://doi.org/10.1016/j.jtcvs.2019.09.050
}

As the scourge of lung cancer continues to take more lives than the other 3 leading causes of cancer, ${ }^{1}$ we have continued to look for better treatments of this catastrophic epidemic. Despite exciting advances including immunotherapy and circulating tumor-DNA sequencing, the overall survival of all newly diagnosed lung cancer has barely changed from the 1970s and continues to be less than $20 \%$, primarily because most cases are diagnosed at advanced stages. ${ }^{2}$

Early stage lung cancer is where we can hope to have any meaningful effect in combatting this disease. In these cases, surgical anatomical lung resection (SALR) continues to be the gold standard that has stood the test of time. Evidence suggests that SALR offers a 5-year survival rate up to $94 \%$ for stage I lung cancer. ${ }^{3}$ Compared with other modalities, SALR provides the most definitive evaluation of treatment including margins, nodal status, and the entire tumor tissue for analysis. In cases of R0 resection, there is never a question of whether some of the tumor escaped the field of treatment. However, SALR, traditionally performed through a rib-spreading thoracotomy, has also been criticized as too invasive and risky.

In an effort to decrease the morbidity of thoracotomy, the surgical approach has undergone dramatic evolution promoting minimally invasive thoracoscopic surgery, whether video-assisted or robotic-assisted as the new standard of care by many thought leaders. Numerous studies have touted the benefits of thoracoscopic surgery over thoracotomy ${ }^{4}$ including a recent study of more than 1100 patients who underwent video-assisted thoracic surgery-SALR with $0 \%$ mortality. ${ }^{5}$ Other studies have also shown the technical and oncologic benefits of the robotic approach. ${ }^{6-9}$

Alongside this surgical evolution, there have also been significant strides in developing more accurate and effective nonoperative ablative modalities especially stereotactic body radiotherapy (SBRT), which has become the de facto alternative to surgical resection of early stage cancer. disease. stay of 4 days.

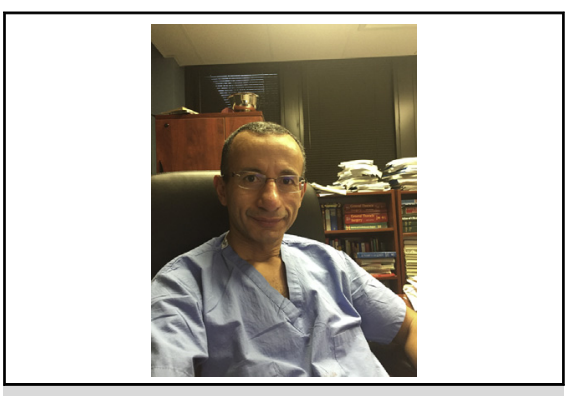

Abbas E. Abbas, MD, MS, FACS

Central Message

By demonstrating a low complication rate after anatomic lung resection, robotic surgery establishes the safety of the surgical management of lung cancer, comparing favorably with nonsurgical modalities.

See Article page 681.

Although often hotly debated, most retrospective and database studies that have compared surgery and SBRT in early stage lung cancer have shown better overall and progression-free survival in the surgical group. ${ }^{10-13}$ Additionally, lung SBRT is not without inherent risk with a rate of major complication of $12.0 \%,{ }^{14}$ a $10 \%$ incidence of chronic pain, ${ }^{15}$ and a rate of symptomatic radiationinduced lung toxicity of up to $15 \%{ }^{16}$ Advocates for SBRT often propagate the entrenched belief by physicians and patients that surgery is associated with unacceptably high morbidity and risk. In fact, we can blame this perception for "lowering the bar" and allowing potentially less effective therapy to be considered for this devastating

In this issue, $\mathrm{Cao}$ and colleagues present a retrospective analysis of postoperative complications after robotic anatomical lung resection from a 4-center experience on 1264 patients who underwent robotic anatomical lung resection for lung cancer from 2002 to $2018 .{ }^{17}$ Only 61 major complications (Clavien grade III or higher) occurred in 52 patients $(4.1 \%)$. Most of these were grade III whereas grade IV occurred in only 4 patients $(0.3 \%)$, and 30 -day mortality rate was $0.6 \%$ ( 8 patients). Also impressive was a $98.8 \%$ R0 resection rate and a median length of hospital

This report mainly focuses on the postoperative portion of the perioperative period with little information given 
on the intraoperative outcomes. The only information is the conversion rate to thoracotomy which was $7 \%$ (89 patients), a rate that is considerably higher than that reported by other studies. ${ }^{18}$ We must assume that a number of those conversions were due to bleeding. Of course, the elephant in the room, especially with robotic surgery is whether the risk of intraoperative complications is higher because the surgeon is not even at the bedside and a large heavy machine is attached to the patient. A few studies have shown the incidence of intraoperative complications in robotic SALR to not be significantly different from other surgical approaches. ${ }^{19}$ However, more information on this important aspect of robotic surgery will be necessary.

In conclusion, this article and others continue to show that short and long-term outcomes for minimally invasive SALR today are much different from those of yesteryear. Indeed, instead of raising the stakes with competing modalities, surgeons must instead raise the bar of expectations in how we treat lung cancer.

\section{References}

1. Siegel RL, Miller KD, Jemal A. Cancer statistics, 2019. CA Cancer J Clin. 2019; 69:7-34.

2. National Cancer Institute. Surveillance, Epidemiology, and End Results Program. Cancer stat facts: lung and bronchus cancer. Available at: https://seer. cancer.gov/statfacts/html/lungb.html. Accessed September 8, 2019.

3. Goldstraw P, Chansky K, Crowley J, Rami-Porta R, Asamura H, Eberhardt W, et al. The IASLC lung cancer staging project: proposals for revision of the TNM stage groupings in the forthcoming (eighth) edition of the TNM classification for lung cancer. J Thorac Oncol. 2016;11:39-51.

4. Higuchi M, Yaginuma H, Yonechi A, Kanno R, Ohishi A, Suzuki H, et al. Longterm outcomes after video-assisted thoracic surgery (VATS) lobectomy versus lobectomy via open thoracotomy for clinical stage IA non-small cell lung cancer. $J$ Cardiothorac Surg. 2014;9:88.

5. Suzuki K, Saji H, Aokage K, Watanabe S, Okada M, Mizusawa J, et al. Comparison of pulmonary segmentectomy and lobectomy: safety results of a randomized trial. J Thorac Cardiovasc Surg. 2019;158:895-907.
6. Shulman RM, Abbas AES. The state of the art and future directions of roboticassisted thoracic surgery. Indian J Thorac Cardiovasc Surg. 2018;34(suppl 1):55.

7. Kent M, Wang T, Whyte R, Curran T, Flores R, Gangadharan S. Open, videoassisted thoracic surgery, and robotic lobectomy: review of a national database. Ann Thorac Surg. 2014;97:236-42; discussion: 242-4.

8. Farivar AS, Cerfolio RJ, Vallieres E, Knight A, Bryant A, Lingala V, et al. Comparing robotic lung resection with thoracotomy and video-assisted thoracoscopic surgery cases entered into the Society of Thoracic Surgeons database. Innovations (Phila). 2014;9:10-5.

9. Park BJ, Melfi F, Mussi A, Maisonneuve P, Spaggiari L, Silva R, et al. Robotic lobectomy for non-small cell lung cancer (NSCLC): long-term oncologic results. J Thorac Cardiovasc Surg. 2012;143:383-9.

10. Hamaji M, Chen F, Matsuo Y, Kawaguchi A, Morita S, Ueki N, et al. Video-assisted thoracoscopic lobectomy versus stereotactic radiotherapy for stage I lung cancer. Ann Thorac Surg. 2015;99:1122-9.

11. Cornwell LD, Echeverria AE, Samuelian J, Mayor J, Casal R, Bakaeen F, et al. Video-assisted thoracoscopic lobectomy is associated with greater recurrencefree survival than stereotactic body radiotherapy for clinical stage I lung cancer. J Thorac Cardiovasc Surg. 2018;155:395-402.

12. Bryant AK, Mundt RC, Sandhu AP, Urbanic J, Sharabi A, Gupta S, et al. Stereotactic body radiation therapy versus surgery for early lung cancer among US veterans. Ann Thorac Surg. 2018;105:425-31.

13. Rosen JE, Salazar MC, Wang Z, Yu J, Decker R, Kim A, et al. Lobectomy versus stereotactic body radiotherapy in healthy patients with stage I lung cancer. $J$ Thorac Cardiovasc Surg. 2016;152:44-54.e9.

14. Yu T, Shin IS, Yoon WS, Rim CH. Stereotactic body radiotherapy for centrally located primary non-small-cell lung cancer: a meta-analysis. Clin Lung Cancer. 2019;20:e452-62.

15. Albers J, Parker W, Kildea J, Pembroke C, Faria S. Chest wall pain following lung stereotactic body radiation therapy using 48Gy in three fractions: a search for predictors. Cancer Radiother. 2019;23:98-103.

16. Kong FMS, Moiseenko V, Zhao J, Milano M, Li 1, Rimner A, et al. Organs at risk considerations for thoracic stereotactic body radiation therapy: what is safe for lung parenchyma? Int J Radiat Oncol Biol Phys. November 26, 2018 [Epub ahead of print].

17. Cao C, Louie BE, Melfi F, Veronesi G, Razzak R, Romano G, et al. Outcomes of major complications after robotic anatomic pulmonary resection. J Thorac Cardiovasc Surg. 2020;159:681-6.

18. Cerfolio RJ, Watson C, Minnich DJ, Calloway S, Wei B. One hundred planned robotic segmentectomies: early results, technical details, and preferred port placement. Ann Thorac Surg. 2016;101:1089-95; discussion: 1095-6.

19. Cerfolio RJ, Bess KM, Wei B, Minnich DJ. Incidence, results, and our current intraoperative technique to control major vascular injuries during minimally invasive robotic thoracic surgery. Ann Thorac Surg. 2016;102:394-9. 